\title{
Educational Responses to Socioeconomic Inequality
}

\author{
Laura Bures \\ Department of Sociology, MacEwan University
}

\begin{abstract}
Socioeconomic inequality continues to be a major concern both internationally and within Canada. Educational outcomes for children are one of the key areas affected by this reality. Schools are considered institutions responsible for promoting the social mobility of children. However, due to increasing social, political, and economic disparities among families, schools have redesigned themselves to ensure this idea persists. This paper examines how parental inconsistencies, lack of supportive home environments, and financial burdens associated with low socioeconomic status families have a negative influence on children's educational outcomes. It investigates why schools have become concerned with implementing programs to help alleviate the effects of socioeconomic inequalities on children and their families. A discussion of the various strategies schools have put in place to integrate struggling children, families, and communities is included. Issues arise in regard to how these programs will be funded, who is responsible for these children within schools, and recommendations going forward. School boards need to be allocated more funding and support from macro level institutions such as the government and health boards if they hope to find a solution.
\end{abstract}

\section{Introduction}

Socioeconomic disparities are known to handicap youth. Children of low socioeconomic status are more likely to fall victim to lifestyle and health related factors that hinder their ability to learn and complete their education. Due to differences in financial resources, support systems, and home environments, major achievement gaps are observed between economically advantaged and disadvantaged children. Schools have recognized that socioeconomic disparities thwart a child's likelihood of doing well in school and achieving social mobility. As rising income inequality continues to be a social, economic, and political concern both internationally and within Canada, schools have expanded their role beyond the traditional educational realm to tackle these inequalities. Education is widely thought of as the driver of social and economic change; the ladder to social mobility. In the most recent years, schools have redesigned themselves to combat these external pressures in the hopes of uplifting future generations of children. As a result, a large number of programs and initiatives have been implemented to address socioeconomic disparities that negatively affect children's educational outcomes. When schools offer programs to support disadvantaged children, social issues affecting the individual, the family, and the community are also addressed. As a result, children will experience fewer barriers in attaining their education. But what social, economic, and cultural transformations have led to educational systems taking on these additional roles, and what are the implications of schools addressing these issues? Questions arise on whether or not schools should become social welfare hubs, and who should be responsible for tackling these issues within schools.

\section{The Effects of Socioeconomic Status on Children in Schools}

What does it mean to be of low socioeconomic status and how might this affect children's educational opportunities? Socioeconomic status is measured by examining an individual's or household's achievements in education, employment, occupational status, income and wealth (Considine \& Zappalà, 2002). Socioeconomic status is the best-known predictor of how much schooling a student will obtain, how well they will do in their studies, and what life prospects will exist for them beyond their schooling (Levin, 1995). This is important because a child's economic and social standing is considered to be an accurate predictor of their life opportunities (Engle \& Black, 2008). Schools are perceived to be the institutions responsible for fostering future generations of youth, yet educational opportunities all over the world depend strongly on social class background 
(Meyer, 2016, p. 339). Conditions of socioeconomic status that have a direct effect on educational attainment and social mobility include: low parental education, low family income, high family stress, and low social standing. This is significant because until issues of social inequality are addressed, children will continue to struggle in school and their chances of social mobility will be limited.

There are a number of studies related to the direct and indirect effects of socioeconomic status on children's educational attainment. Ferguson, Bovaird, \& Mueller (2007) found that children from low socioeconomic status families often start school already behind their peers who come from more affluent families; a concept known as school readiness (p. 701). Children from low-income families do not receive adequate stimulation at home or learn the necessary social skills required to prepare them for school. Typical problems include parental inconsistency in daily routines, changes in primary caregivers, lack of adequate supervision, and poor role modelling (Ferguson, Bovaird, \& Mueller, 2007). In general, parents from low socioeconomic backgrounds lack the necessary economic and social resources needed to prepare their child for school. Limited resources leave them unable to promote their child's learning due to an inability to provide quality child care, educational materials, and visits to museums or libraries (Shonkoff \& Phillips, 2000). In contrast, parents who are advantaged socially, educationally, and economically foster a higher level of achievement in their children by providing higher levels of social or psychological support within their home. These families are more likely to recognize the importance of reading to their child at home, providing them educational resources, and actively challenging their learning abilities. These home environments encourage the development of skills necessary for a child's success in school (Considine \& Zappala, 2002). Children who lack these supportive environments due to a disadvantaged socioeconomic status face a greater number of barriers that impede their ability to learn.

Parents of low socioeconomic status also face more hurdles in regard to parenting as a result of their unstable work schedules. It is not uncommon for these parents to have multiple jobs or fluctuating work schedules (Considine \& Zappala, 2002). A consequence related to this lack of time is that these parents are less likely to supervise their child's schoolwork and maintain appropriate levels of discipline. Economically, their limited income may situate them in a position where they are less likely to purchase or provide resources that support their child's development including nutritious meals, enriched home-learning environments and stimulating neighborhood environments (Duncan \& Magnuson, 2003). Research by the Institute of Research and Public Policy (Montreal, Quebec) shows that differences between students from low and high socioeconomic neighbourhoods were evident by grade 3; children from low socioeconomic neighbourhoods were less likely to pass a grade 3 standards test (Brownell, Roos, \& Fransoo, 2006). Socioeconomic status has such a profound impact on education that until this issue is addressed, children will continue to be disadvantaged.

Low parental education and high family stress are other components of socioeconomic status considered detrimental to a child's education. These factors have a negative influence on a child's cognitive development and academic achievement (R.A. Malatest \& Associates, 2015). Coming from a disadvantaged socioeconomic background results in children entering schools with "dispositional skills and knowledge that can impede their ability to conform to institutionalized expectations" (Lareau, 2003, p. 588). For example, parental education is noted to be one of the most stable indicators of socioeconomic status that influences educational attainment among children (R.A. Malatest \& Associates, 2015). Parents who are highly educated are more likely to enrol their children in educational summer camps, after-school care, and tutoring programs (Engle \& Black, 2008). This is because educated parents are more likely to work well-paying jobs, have a steady income and experience housing stability (Considine \& Zappala, 2002). As a result, these families often have access to a greater number of economic resources in which they can invest in their child's education (de Neubourg, Borghans, Coppens, \& Jansen, 2018). Therefore, children from affluent families are at an advantage from a young age over children who come from low socioeconomic families because they have more resources to support their education. In order to equalize the educational playing field, schools must address these issues. Tackling educational disparities means recognizing that children enter into the school system at different levels based on socioeconomic conditions and parental upbringing.

Secondly, parents of low socioeconomic status who are stressed out and overwhelmed by the pressures of their life circumstances are unable to meet the emotional, cognitive, and caregiving needs of their children (Duncan et al., 2007). Researchers have found that children born into low socioeconomic families are more likely to experience parental stress and agitation growing up, which is harmful to their cognitive and emotional development (Duncan et al., 2007). These families often experience stress related to income, employment, and housing arrangements. For example, there is a greater likelihood of frequent or disruptive changes in both housing arrangements and child care among these families. These factors have been found to disrupt a child's sense of stability and social development (Sandstrom \& Huerta, 2013). Research has shown that children of low socioeconomic status have lower reading levels, cognitive abilities, and social skills among early years 
of schooling which may hinder their educational attainment and chance of social mobility (Sandstrom \& Huerta, 2013). Schools have recognized that the only way to address inequality is to find a way to support disadvantaged children by creating social service links between families and communities. Children need extra support outside of their school day, and if parents are not around to offer this support, schools must step in. Otherwise, children will fall behind, and achievement gaps will continue to widen. By failing to address the socioeconomic disparities that effect children's cognitive, social, and emotional development outside of the home, educational inequality will continue to exist, and chances of social mobility will be limited.

\section{Why Are Schools Intervening?}

To understand why schools have transitioned into institutions that advocate for child welfare, one must understand how societal views on inequality have changed. Pierre Bourdieu suggests that the attributes an individual has in relation to their social position such as skills, credentials, education or disposable income can act as a major form of social inequality (Bourdieu, 1982/1991). Bourdieu argues that the forms of capital an individual acquires may help or hinder their chance of social mobility. For example, having economic or cultural capital is a privilege within education systems because of an increased availability of supportive resources (Bourdieu \& Passeron, 1970/1990). Over the last few decades, schools have questioned how to address socioeconomic inequality. Levin (1995) examined educational responses to poverty by looking at how schools are dealing with this issue. He concludes that "although schools cannot solve problems of poverty on their own, they are able to assist poverty's victims to understand and advance their own welfare" (p. 221). In support of this idea, a growing number of schools have implemented programs to support low socioeconomic students. This is because schools have recognized that until external factors affecting children outside of a school setting are addressed, socioeconomic inequalities will continue negatively affect children. Social mobility will not exist until every child has an equal chance of being successful in school, regardless of their socioeconomic status.

Schools have begun to intervene with child welfare due to the simple fact that education is so directly affected by consequences of poverty (Levin, 1995). Engle \& Black (2008) explain that the alleviation of poverty demands not only economic solutions, but the adoption of strategies by schools, governments, communities, and families that alter the processes whereby poverty can disadvantage child development. Therefore, intervention programs are needed within schools in order to enable children and families to develop positive interactions that can be sustained through education. Poverty will continue to disadvantage children if schools are the only source of stability in their lives. There is a growing consensus that families of low socioeconomic status need extra support and resources to ensure their child will succeed in school. Without the adequate linkages between schools, family and community, a child will fall behind because they will leave their school on a daily basis to go back to an environment that does not promote their educational success. As a result, schools are now advocating for quality early learning education, after-school care programs, and parent-child support services in the hope to support children both inside and outside of the educational setting (Ferguson, Bovaird, \& Mueller, 2007).

In relation to other social factors that hinder a child's education, Cooper (2010) found that low income parents often work long hours in multiple and/or physically demanding jobs for minimal pay. As mentioned before, these parents are less involved in supporting their child's education at home due to a lack of time and energy. Schools have recognized that although this is a social issue, they can help alleviate its effects by offering extra support for these families. In response, educational after-school care programs and free tutoring are now common within schools. These programs are necessary because they help support children's learning and social development which may otherwise be ignored at home (Cooper, 2010). After-school care programs also benefit parents who may be unable to afford adequate child care. There is also a greater demand for parental involvement within education (Engle \& Black, 2008). Schools have become increasingly concerned with this concept. Cooper (2010) found that the lack of communication between schools and families of low socioeconomic status can negatively affect a child's education. Research suggests that by providing families with information on how schools function and how they can support their child's learning, schools can encourage parental involvement within education. Strengthening connections between schools and families through parent outreach programs and school family counsellors promotes academic achievement among low socioeconomic status children (Cooper, 2010). When schools act as facilitators between children, families, and communities, students have greater supportive resources to do well in school. Therefore, when schools expand beyond curriculum, social mobility of children is promoted, and socioeconomic inequalities are lessened. A child will have a greater chance at succeeding in school if they are supported both inside and outside of the educational setting.

Schools have begun to tackle social, economic and cultural issues mainly because "rising income inequality continues to be an economic, social, and political concern both internationally and within Canada" (CPA Canada, 2017, p. 
1). The cost of living and costs of child care services have increased, alongside the gap between the rich and the poor. But why in the last 20 years have schools expanded outside of their traditional educational realm to tackle these social issues? In The Sociology of Education in Canada, Wotherspoon (2018) explains, "education systems are undergoing substantial modification as they come to be aligned with fundamental social, economic, and cultural transformations" (p.332). In the last 20 years there has been an increasing demand for youth to enter into the workforce with a post-secondary degree. Today, a high school-diploma is no longer considered to be a safe guard against poverty. As the economy continues to change, we have seen an increase in specialized jobs that require new knowledge and training. Therefore, holding a degree is now considered a necessity for youth if they want to successfully enter the workforce, acquire a well-paying job, and ensure they are able to adequately support themselves. To summarize, low educational achievement leads to fewer economic prospects later in life, perpetuating a lack of social mobility across generations.

Schools have recognized that if children are disadvantaged by socioeconomic conditions from a young age, their chances of finding themselves in well-paying careers and being able to support themselves is limited. Education systems have taken responsibility to address these disparities because of an increased understanding that fostering healthy child development requires leveraging the entire community. Since schools are one of the few institutions able to target children and their families from an early age and are the main institutions responsible for educating future generations of youth, societal demands have weighed on them to take the initiative. Unless inequalities are tackled at the earliest level possible, income distribution will continue to be disproportionate, and socioeconomic disparities will continue to be perpetuated within education. Therefore, education systems have taken additional roles in the hopes of addressing and changing socioeconomic inequalities, rather than reflecting them. This transformation is tied to the changing economy, workforce, costs of child care, and cost of living that has transpired over the last few decades (Wotherspoon, 2018). In a world that is becoming more global, diverse, and competitive, it is now more important than ever to tackle socioeconomic inequalities that have the potential to harm future generations of children. As labour markets, political conditions, and the economy continue to change, unless children are well educated and equip to make do in this world, they will fall behind.

\section{What Initiatives Should Schools Take?}

Perspectives on the causes of socioeconomic inequalities have changed. Sociologists have recognized poverty as a societal problem, rather than an individual one (Engle \& Black, 2008). Critical understandings of this issue are now focused on various institutional conditions and social exclusion practices which prevent groups or categories of people from moving out of poverty (Engle \& Black, 2008). Until poverty is recognized as a societal issue that is present and reproduced within social institutions, children will continue to be disadvantaged. These inequalities can only be addressed if schools, the family, the community, and the government step up and link together to implement programs and initiatives. Since schools are meso level institutions, they have the power to influence both individual and macro level institutions. Educational researchers have recognized the need for schools to adopt more formal policies between social institutions to address inequality and ensure the social mobility of future generations of children (Engle \& Black, 2008). Recommended initiatives include government advocacy, community outreach programs, and funding to support school boards that strive to achieve equity of outcomes (Ferguson, Bovaird, \& Mueller, 2007). Advancing children's academic outcomes is necessary to promote the economic and social health of a community as a whole (Horn, Freeland, \& Butler, 2015). By addressing socioeconomic disparities, schools can ensure that all children have the right to a fulfilling education and an opportunity for social mobility regardless of their life circumstances.

Without adequate linkages between social institutions such as families and communities, socioeconomic inequalities will continue to negatively affect children's educational experiences So what types of initiatives do schools need to take? Ferguson, Bovaird \& Mueller (2017) suggest that family support networks should be offered within schools to encourage parental awareness of the following practices and procedures: positive role modelling, benefits to reading with children at home, proper nutrition planning, family budgeting and healthy child development. Schools can help connect low socioeconomic status families to community programs and services including message boards of organizations within the community which provide accessible child-care, head-start programs, summer camps, tutoring services and financial and mental health resources (Ferguson, Bovaird, \& Mueller, 2007). Through the use of integrated strategies with communities and health agencies, schools can better address issues affecting children beyond school boundaries. For example, when schools take initiatives to offer breakfast and lunch programs or provide nutritional support resources to families, this change in health can influence students' academic outcomes. In turn, these "academic outcomes can 
influence the economic and social health of a community, often in unpredictable ways" (Horn, Freeland, \& Butler, 2015 , p. 1). Creating interdependencies among schools, families, communities and health boards can ensure social inequality is being addressed in a multi-faceted manner. These efforts will ensure that every child has a chance of educational opportunity and social mobility regardless of socioeconomic status.

\section{Discussion}

When schools implement programs to support disadvantaged children, social issues affecting the individual, the family, and the community are also addressed. Schools should be viewed not only as educational institutions, but as community centres, counselling agencies, and social-service centres (Horn, Freeland, \& Butler, 2015). Schools are able to support children's and families' needs by offering programs to support them both inside and outside of the educational setting. These programs can help alleviate the effects of socioeconomic inequalities on children, families, and communities. Schools can ensure that the social mobility of children is promoted by addressing both macro and micro level institutions. Researchers argue that actively challenging socioeconomic inequalities can help decrease the likelihood that poverty will influence education (Engle \& Black, 2008). There is however, a need for greater advocacy and funding of education systems by the government if we want to ensure children are not disadvantaged by the socioeconomic conditions they are born in to. By implementing formal policies and advocating for increased funding, schools may be able to influence governments and health boards to address socioeconomic disparities. Such efforts include advocating for quality early education, mental health support within schools, after-school care, intervention programs, and more social service workers within the institution (Ferguson, Bovaird, \& Mueller, 2007). These initiatives will ensure that every child can receive a quality education.

Unfortunately, educational researchers have recognized that there are various challenges related to schools tackling socioeconomic issues which lie outside of their traditional educational role. For one, many of these initiatives call upon increased school board funding by the government to support these individuals, families, and communities. Some argue that it is not the government's responsibility to intervene with these issues (Wotherspoon, 2018). This controversy will likely persist due to the fact that a large population of people still consider poverty to be an individual issue rather than a societal once. Whether or not this public perception will change can only be determined by shifting political and economic perspectives in the decades to come. Second, educational researchers have recognized that tackling socioeconomic disparities should not be solely be left up to the teachers within schools. Teachers struggle enough with their occupational demands, heavy workloads and stress (Wotherspoon, 2018). For example, a study on Alberta teachers' time use has revealed that over half of teachers' work is devoted to activities outside of in-class instruction (R.A. Malatest \& Associates, 2015). Apart from meeting the demands of curriculum, they must attend to the diverse needs of students, administration, and other school-related activities. Outside of the classroom they are required to plan lessons, meet with parents, manage extracurricular activities, and upgrade their professional skills (R.A. Malatest \& Associates, 2015). Educational researchers have recognized that they cannot call on teachers to be the sole advocates for the alleviation of children's socioeconomic disparities (Wotherspoon, 2018). It would be outrageous to assume that all teachers are capable of attending to every child's needs, both inside and outside of the classroom. School boards need to increase the number of specialized workers, educational assistants and social workers within classrooms. Teachers need an array of resources and personnel in order to attend to the needs of children from low socioeconomic backgrounds (Wotherspoon, 2018). School boards should also consider offering training for teachers and school faculty on how to support children who come from disadvantaged backgrounds. An example of this would be cultural diversity training. This training can help increase awareness, attitudes and skills on how to support the development of children from low socioeconomic status families. This training should be offered during a time that is convenient for teachers such as summer holidays or professional development days. By providing teachers with resources on how to support children of low socioeconomic status, schools can ensure that every child's chance of social mobility is prioritized. An increased number of mental support staff for children and families would also help alleviate the effects of stress on children that harms their learning. By hiring trained professionals who can address issues pertaining to individual's families, these staff can better understand how a child's home environment may be hindering their education. Once specific barriers are identified, staff have the potential to implement support for these children and families to ensure their education remains a priority.

What implications would educational systems experience by taking on these additional roles and how would society change once these programs and initiatives are put in place? To start, families would have increased support regarding their children's mental health, academic performance, and cognitive and emotional development. If schools offer outof-school care programs and summer camps, economic factors affecting families such as the inability to pay for adequate child care would decrease. If schools became community hubs, issues affecting children outside of the educational realm could be better addressed. For example, by 
offering counselling, parenting classes, and at home nutrition support, schools can address issues related to socioeconomic status that go beyond the educational context and affect broader social spheres. Children would be more equipped to attain an education and enter the workforce with the skills necessary for them to be successful in future economies. In general, if schools took on additional roles to tackle socioeconomic issues, chances of social mobility would no longer be dependent on socioeconomic status. This could help decrease social stratification and alleviate effects of poverty on future generations. Children would no longer be in a position where their future careers are dependent on the life circumstances they were born into. Values related to hard work and academic excellence would have a greater influence over socioeconomic status in assessing one's life chances. Innovation would be better promoted in a society that advocates for educational inequality.

\section{Conclusion}

Over the last decade, schools have expanded outside of their educational realm to help alleviate the effects of poverty. This expansion is due to widening income disparities among low socioeconomic families who are living in an increasingly globalized and competitive world. Schools are institutions designed to promote social mobility. With adequate support, they can help ensure that future generations of children are well-educated and prepared to enter a dynamic everchanging society. Unfortunately, socioeconomic status situates children differently upon entering formal schooling. Schools must link together with families, communities, and social service agencies to come up with integrated solutions to minimize socioeconomic disparities among children. In order for schools to promote children's educational attainment and social mobility, they require funding and support for resources that span both within the intuition, and outside into the community. Since schools are meso level institutions, they have influence over micro level issues that affect children, families, and communities. By partnering with health boards and social service agencies, school boards may be better equipped to lobby for support and funding from the government. School boards must address the need for a greater number of trained workers within schools to support disadvantaged children. Introducing mental health workers, educational assistants, and social workers within schools can help ensure children's issues are being addressed, and teachers can focus on teaching. School faculty should be given the opportunity to receive cultural diversity training and resources to ensure they support educational attainment and social mobility for every child. By developing relationships with families, communities, and health boards, schools can help identify common problems that make it difficult for individuals to succeed. By implementing programs to alleviate the effects of these issues through the use of integrated approaches, schools can better support children whose life opportunities may be at risk due to socioeconomic disparities.

\section{References}

Bourdieu, P. (1991). Language and symbolic power (G. Raymond, $\&$ M. Adamson, Trans.). Cambridge: Polity Press and Harvard University Press. (Original work published 1982). Retrieved from: https://monoskop.org.

Bourdieu, P., \& Passeron, J.P. (1990) Reproduction in education, society, and culture. (R. Nice, Trans.). London: Sage Publications. (Original work published 1970). Retrieved from:

htps://monoskop.org

Brownell, M., Roos, N., \& Fransoo, R. (2006). Manitoba Centre for Health Policy. Is the class half empty. Choices, 12, 3-30. Retrieved from https://irpp.org/

Considine, G., \& Zappalà, G. (2002). Factors influencing the educational performance of students from disadvantaged backgrounds. In T. Eardley, \& B. Bradbury (Eds.), Competing visions: Refereed proceedings of the national social policy conference (Vol. 2001, pp. 91-107) Retrieved from: semanticscholar.org

Cooper, C. E. (2010). Family poverty, school-based parental involvement, and policy-focused protective factors in kindergarten. Early Childhood Research Quarterly, 25(4), 480-492. doi.org/10.1016/j.ecresq.2010.03.005

CPA Canada, (2017, August 29). The urban dilemma of Canada's income inequality problem. Retrieved from https://www.cpacanada.ca/

de Neubourg, E., Borghans, L., Coppens, K., \& Jansen, M. (2018). Explaining Children's Life Outcomes: Parental Socioeconomic Status, Intelligence and Neurocognitive Factors in a Dynamic Life Cycle Model. Child Indicators Research, 11(5), 1495-1513. doi:10.1007/s12187-017-9481-8

Duncan, G. J., Dowsett, C. J., Claessens, A., Magnuson, K., Huston, A. C., Klebanov, P., \& Sexton, H. (2007). School readiness and later achievement. Developmental Psychology, 43(6), 14281446. doi. 10.1037/0012-1649.43.6.1428.

Duncan, G. J., \& Magnuson, K. A. (2003). Off with Hollingshead: Socioeconomic resources, parenting, and child development. In M.H. Bornstein (Ed.), Socioeconomic status, parenting, and child development (pp. 83-106). Mahwah, NJ: Erlbaum Associates. Retrieved from https://childrenshealthwatch.org

Engle, P. L., \& Black, M. M. (2008). The effect of poverty on child development and educational outcomes. Annals of the New York Academy of Sciences, 1136(1), 243-256. doi:101.1196/annals.1425.023.

Ferguson, H. B., Bovaird, S., \& Mueller, M. P. (2007). The impact of poverty on educational outcomes for children. Paediatrics \& Child Health, 12(8), 701-706. doi: 10.1093/pch/12.8.701.

Horn, M. B., Freeland, J., \& Butler, S. M. (2015). Schools as community hubs: Integrating support services to drive educational outcomes. Discussion Papers on Building Healthy Neighborhoods, (3). Retrieved from https://brookings.edu 
Levin, B. (1995). Educational responses to poverty. Canadian Journal of Education/Revue canadienne de l'éducation, 211-224. Retrieved from: https://journals.sfu.ca

Meyer, K. (2016). Why should we demand equality of educational opportunity?. Theory and Research in Education, 14(3), 333347. doi:10.1177/1477878516676709.

Phillips, D. A., \& Shonkoff, J. P. (Eds.). (2000). From neurons to neighborhoods: The science of early childhood development. Washington, DC: National Academies Press. doi:10.17226/9824

R.A. Malatest and Associates. (2015). Alberta teacher workload study. Alberta Education. [Report]. Retrieved from: https://education.alberta.ca

Sandstrom, H., \& Huerta, S. (2013). The Negative effects of instability on child development: a research sysnthesis. Washington, DC: Urban Institute. Retrieved from https://urban.org./research/publications

Wotherspoon, T. (2018). The sociology of education in Canada. 5th Edition. Toronto, ON: Oxford University Press. 